\title{
Quiste hidatídico mediastínico. Reporte de un caso y revisión de la literatura
}

\author{
Carlos Álvarez Z., Pedro Riveros S., Rubén Miranda T. y Oriana Yarur V.
}

\section{Mediastinal hydatid cyst. Case report and review}

Hydatid disease is caused by the larval stages of a cestodes belonging to the genus Echinococcus. In humans, hydatid larva and cysts are located $>90 \%$ in the liver and/or lungs. Primary mediastinal location, with absence of documented lung infection, is extremely rare and has not been previously reported in Chile. We report the first case of a primary mediastinal hydatid cyst in Chile and review the literature. A 38 year old woman was admitted because of a painful right supraclavicular mass, dyspnea on exertion and logical dysphagia. Presurgical evaluation evidenced a mediastinal tumor extending to the cervical region that was successfully removed. The diagnosis of mediastinal hidatyd cyst was confirmed macroscopically and by biopsy.

Key words: Hydatid cyst, mediastinal cyst, mediastinal tumor.

Palabras claves: Quiste hidatídico, quiste de mediastino, tumor de mediastino.

\section{Introducción}

$\mathrm{L}$ a hidatidosis es una parasitosis producida en Chile por la larva de la tenia Echinococcus granulosus. La infección accidental de los seres humanos ocurre después de la ingestión de los huevos del cestodes excretados por el hospedero definitivo (caninos). Una vez ingeridos los huevos, a través del duodeno, pasan a la circulación portal. Finalmente, el huevo se transforma en la larva, hidátide, que en más del $90 \%$ de los casos, se localiza en el hígado o en el pulmón. En sólo un pequeño porcentaje $(<10 \%)$, los parásitos logran traspasar el filtro hepático y pulmonar y, por vía sanguínea, afectar a otros órganos como el bazo, el riñón, el páncreas, el cerebro y el corazón, o bien, llegar a localizaciones inusuales ${ }^{1-6}$. La localización mediastínica, sin enfermedad pleuropulmonar previa, es extremadamente infrecuente, estimándose su incidencia en 0,1 a $0,5 \%$ de todas las hidatidosis intratorácicas ${ }^{2}$. Se han publicado tan sólo un poco más de cien casos en la literatura internacional ${ }^{3}$. No encontramos reportes previos en Chile.

Comunicamos el primer caso de un quiste hidatídico $(\mathrm{QH})$ de mediastino en Chile, operado por los autores en el Servicio de Cirugía del Complejo Asistencial Barros Luco (CABL). Se describe el cuadro clínico, su tratamiento y resultado, adjuntando las imágenes y los hallazgos radiológicos más destacados. En la discusión presentamos una revisión bibliográfica actualiza- da del tema. Para tal revisión se realizó una búsqueda a través de los índices PubMed y scielo.cl sin restricción de tiempo o idioma.

\section{Caso clínico}

Mujer de 38 años de edad, portadora de diabetes mellitus tipo II en tratamiento con hipoglicemiantes orales. Natural de la ciudad de Temuco (Chile, IX Región) donde vivió hasta los 25 años, teniendo contacto habitual con caninos. Se trasladó a Santiago donde continúa habitando con animales domésticos.

Consultó en el policlínico de otorrinolaringología por cuadro de 20 meses de evolución, caracterizado por aumento de volumen progresivo y doloroso en la región lateral derecha del cuello, con disnea a grandes esfuerzos y disfagia ilógica ocasional. Al examen físico destacaba un aumento de volumen cervical derecho, fluctuante y levemente doloroso a la palpación. Se solicitó TAC de cuello, observándose una masa supra e infraclavicular derecha de aproximadamente 5 $\mathrm{cm}$ de diámetro, con múltiples tabiques en su interior, que comprometía hacia caudal, el mediastino posterior y medio derecho, con extensión superior hasta la región paratraqueal del mismo lado. Se concluyó que era compatible con la existencia de infiltración nodal de naturaleza incierta. El estudio se complementó con TAC de tórax (Figuras 1 y 2) que mostró en el
Complejo Asistencial Barros Luco. Santiago, Chile Servicio de Cirugía, Equipo de Cirugía Torácica (CAZ, PRS) Universidad de Santiago, Santiago, Chile

Estudiante de Medicina (RMT, OYV)

Recibido: 25 noviembre 2005 Aceptado: 28 junio 2006

Correspondencia a: Carlos Álvarez Zepeda cmaz@vtr.net 
Figura 1. Imagen del tumor (T) de mediastino que no capta medio de contraste en la ventana mediastínica de la TAC de tórax. Se observa su relación con la traquea.

Figura 2. Imagen del tumor (T) de mediastino en la ventana pulmonar de la TAC de tórax. Se observa su relación con la carina principal y los grandes vasos.

Figura 3. Imagen intraoperatoria donde se observa el tumor (T) y su relación con la cava superior (CS), el corazón y pericardio (C-Pr) y el pulmón (P).

Figura 4. Imagen intraoperatoria donde se observan los quistes hidatídicos una vez abierta la pleura mediastínica.
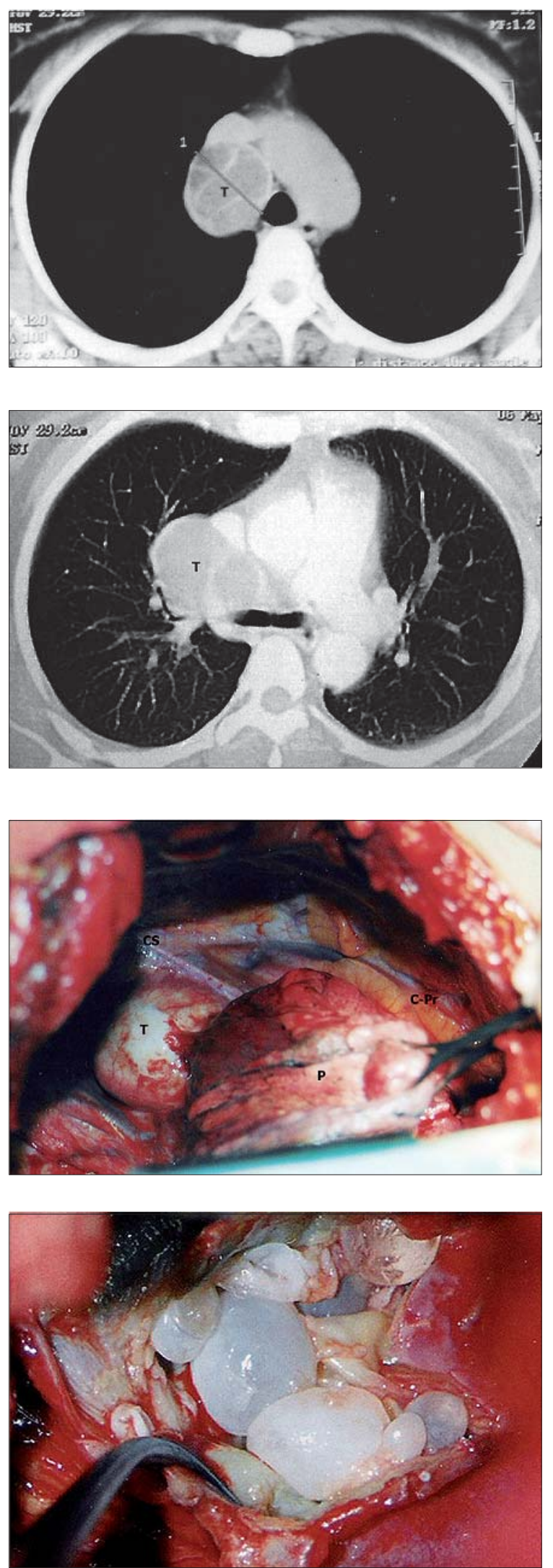

mediastino medio y posterior una imagen quística que no captaba medio de contraste, de $5 \mathrm{~cm}$ en su eje mayor, adyacente a la traquea en su parte caudal y a tiroides en su porción cefálica. Además, en el examen se apreciaban algunas imágenes intersticiales pulmonares bilaterales, mayores a izquierda y asociadas a unas bulas de aspecto residual. No se visualizaron linfonodos. Se concluyó en este examen que la imagen era compatible con un tumor de mediastino con extensión cervical, de naturaleza desconocida. La paciente fue derivada a la Unidad de Cirugía de Tórax para tratamiento definitivo. Los exámenes pre-operatorios mostraban leucocitos de 5.000 células $/ \mathrm{mm}^{3}$, con $2 \%$ de eosinófilos, hematocrito de 40,3\%, hemoglobina 14,1 $\mathrm{mg} / \mathrm{dl}$, exámenes de función renal normal, protrombinemia normal y electrocardiograma normal.

Fue abordada mediante toracotomía posterolateral derecha lográndose visualizar un tumor mediastínico de aspecto multinodal que abarcaba desde la base del cuello hasta el nivel de la vena ácigos (Figuras 3 y 4). Al efectuar la toma de muestra para biopsia rápida intra-operatoria se observaron membranas, líquido y vesículas hijas típicas de $\mathrm{QH}$ que se retiraron y aspiraron (Figura 5). Se realizó entonces periquistectomía total instilándose solución salina hipertónica estéril al $3 \%$ a las cavidades residuales. Los pulmones y la pleura tenían aspecto macroscópico normal. El resultado de la biopsia rápida intra-operatoria y la diferida confirmó el diagnóstico de $\mathrm{QH}$ multivesicular. En el post-operatorio presentó una neumonía basal derecha que se trató, empíricamente, con ceftriaxona con resultado satisfactorio. Fue dada de alta en buenas condiciones y se mantuvo en controles periódicos en la policlínico de la especialidad.

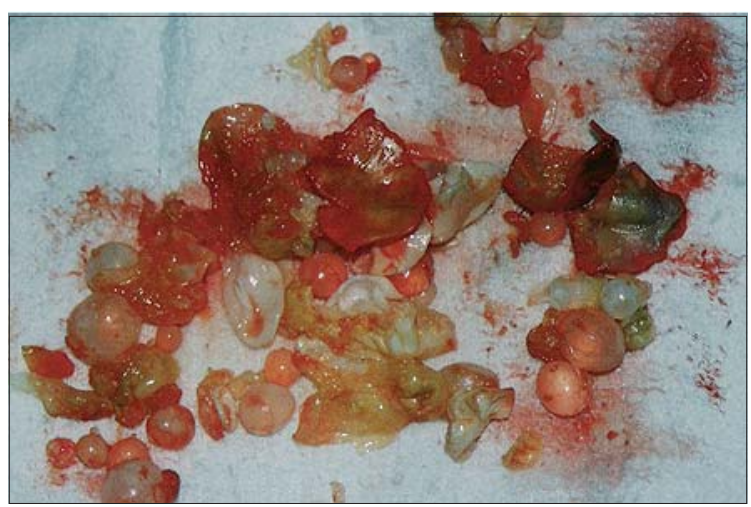

Figura 5. Pieza operatoria donde se observan algunos quistes intactos, vesículas hijas y pleura mediastínica resecada. 
Se le efectuó una nueva TAC de tórax a los siete meses de la intervención que no mostró enfermedad. A dos años de su intervención quirúrgica, permanece en control y seguimiento. Persiste asintomática y sin evidencias clínicas y radiológicas de recidiva, ni de localización de $\mathrm{QH}$ en otros órganos blanco.

\section{Discusión}

El QH, determinado por el desarrollo del estado larval de Echinococcus granulosus, es una enfermedad endémica en Chile. Su incidencia en el país se estima entre 7,5 y 8,3 casos por 100.000 habitantes $^{7,8}$. El perro es el reservorio definitivo más común del parásito; cuando un perro parasitado defeca, libera infinidad de huevos microscópicos al medio ambiente, siendo ingeridos por el ganado ovino. En el tracto gastrointestinal de estos hospederos intermediarios, los huevos eclosionan, penetran la pared intestinal, para alcanzar el hígado vía el sistema porta y desde allí son distribuidos por vía sanguínea a los pulmones y otros órganos. El hombre es un hospedero intermediario aberrante, porque corta el ciclo en el estado de quiste, siendo el hígado el principal órgano afectado $(59-75 \%)$, seguido por los pulmones $(15-27 \%)^{9}$. La poca frecuencia de las localizaciones extra-hepática y extrapulmonar, se debe a que estos dos órganos actúan como filtros biológicos y atrapan a la gran mayoría de los embriones hexacantos, que son los originarios de los quistes ${ }^{10,11}$. Se han descrito otras vías alternativas para el paso de los embriones, como las anastomosis porto-cava o la circulación linfática a través del conducto torácico ${ }^{3}$. Incluso se ha postulado la inhalación directa de huevos hacia el aparato respiratorio ${ }^{12}$. Tal vez, estas vías inusuales de contagio o diseminación, podrían explicar el desarrollo de hidatidosis en lugares inhabituales, como el mediastino.

La sintomatología va a depender del tamaño del quiste, su localización y el compromiso de las estructuras vecinas. Así, si se localiza en el mediastino posterior, puede originar invasión del espacio paravertebral y manifestarse a través de una paraplejía o hemiplejía ${ }^{1,15}$. Si se localiza en el mediastino medio, puede comprometer grandes vasos, arco aórtico, pericardio (pudiendo provocar perforación o taponamiento cardíaco) y síndrome de lóbulo medio ${ }^{1}$. En caso de una localización anterior, el síntoma más frecuente es la disnea por compresión traqueal ${ }^{1-3}$. Si es de ubicación superior, podría llegar a originar un síndrome de vena cava superior o un síndrome de Bernard-Horner ${ }^{1,16}$. Se describe también en la literatura que por compresión de los vasos pulmonares, puede simular un cuadro de estenosis congénita, irritar el nervio frénico o perforar la arteria subclavia por crecimiento a partir del espacio paraesternal ${ }^{1,5}$. Nuestro caso se manifestó por un aumento de volumen evidente de la región cervical, no descrito con anterioridad para esta ubicación y, fundamentalmente, por disnea leve de esfuerzo con disfagia ocasional, lo que representa compresión de traquea y esófago.

La localización mediastínica de un $\mathrm{QH}$ puede originar dificultades diagnósticas ya que, en general, puede ser indistinguible de otras lesiones quísticas del mediastino. Si bien la sospecha inicial del quiste suele ser por radiografía simple, los exámenes de elección son la TAC de tórax y la ecografía que, además, permiten una adecuada planificación terapéutica ${ }^{3,9,13}$. En los casos dudosos o en pacientes alérgicos a contrastes yodados, la RM, con su alta resolución y la posibilidad de obtener imágenes en múltiples planos, facilita el diagnóstico ${ }^{3}$. También se puede usar para el diagnóstico algunos exámenes serológicos o pruebas cutáneas, aunque éstos adolecen de falsos positivos o negativos ${ }^{14}$.

Dentro de las complicaciones, la rotura del quiste, independiente de su localización, puede originar un cuadro de extrema gravedad por choque anafiláctico ${ }^{8}$. La eosinofilia se presenta en 20 a $40 \%$ de los casos, asociada, generalmente, a rotura reciente del quiste ${ }^{5}$.

El tratamiento de los $\mathrm{QH}$ de mediastino es quirúrgico, siendo la periquistectomía la técnica de elección ${ }^{1-5}$. Sin embargo, en algunos casos, la gran adherencia del quiste a las estructuras adyacentes impide su resección total, por lo que en estos casos un suficiente drenaje con aspiración del quiste y extirpación parcial de la cavidad, puede ser lo más adecuado ${ }^{1,3}$. Para la prevención de la equinococosis secundaria, históricamente se ha usado un producto escolicida ${ }^{17}$. No existe el escolicida quirúrgico ideal de aplicación intraquística o local, letal para el parásito e inocuo para los tejidos circundantes. La solución clorurada hipertónica estéril en concentraciones variables (3 al 33\%) fue introducida por el cirujano uruguayo Velarde Pérez Fontana y ha demostrado ser eficaz clínica y experimentalmente ${ }^{18-20}$. En nuestro hospital la solución clorurada hipertónica ha sido el escolicida de preferencia, sin encontrar las serias complicaciones que se han descrito en la literatura $^{21}$.

Aunque la mortalidad atribuida directamente a la hidatidosis es muy baja, reportándose tasas entre 0,29 y $0,6 \%{ }^{22}$, la morbilidad puede tener una repercusión económica y social importante, consumiendo significativos recursos de salud. Otro problema no resuelto es el alto índice de recidiva, que varía de 9,5 a 30\% según estadísticas de diferentes autores ${ }^{23}$.

En relación con la opción de complementar el tratamiento quirúrgico de nuestra paciente con un antipa- 
rasitario, a fin de hacer profilaxis de recidiva en el postoperatorio, es importante comentar que en nuestro hospital no lo empleamos, ya que con albendazol empleado con fines terapéuticos se reportan en la literatura resultados muy diversos ${ }^{24-28}$. La bibliografía está de acuerdo con que albendazol estaría indicado cuando la cirugía no es posible o es probable que no sea efectiva; en pacientes que rechazan la cirugía o bien, como primera aproximación terapéutica. Por otro lado, el anti-parasitario presenta, una vez suspendido, una tasa de recurrencia considerable y efectos adversos que no son despreciables ${ }^{19,27}$.

Nuestra paciente es el primer caso reportado en Chile de un QH de mediastino multivesicular, con buen resultado al tratamiento quirúrgico y evolución favorable tras dos años de seguimiento. Como conclusión podemos señalar que si bien los $\mathrm{QH}$ de mediastino son infrecuentes, deben tenerse en cuenta como diagnóstico diferencial en los tumores de mediastino y en las masas cérvico-torácicas, sobre todo en nuestro país, donde la hidatidosis es una zoonosis endémica.

\section{Resumen}

La hidatidosis es una parasitosis producida por la larva o quiste del cestodes del género Echinococcus. Una vez que el parásito infecta al hombre se ubica, en más de $90 \%$ de los casos, en hígado o pulmón. La localización mediastínica sin afección pleuropulmonar previa es extremadamente infrecuente. En Chile no hay reporte de casos con tal ubicación. Se presenta el primer caso en Chile de un quiste hidatídico $(\mathrm{QH})$ mediastínico: el caso de una mujer de 38 años que consultó por aumento de volumen doloroso supraclavicular derecho, asociado a disnea de esfuerzo y disfagia lógica, cuyo estudio preoperatorio mostró un tumor de mediastino con extensión cervical de aspecto nodal y de naturaleza incierta. Se operó con éxito en nuestro hospital, comprobándose durante la operación y por la biopsia, el diagnóstico de $\mathrm{QH}$ mediastínico. Adjuntamos las imágenes más relevantes y las fotografías de la operación y la pieza quirúrgica, como también una revisión de la literatura médica.

\section{Referencias}

1.- Pedrero Campos C, Sanjuán Rodríguez $\mathrm{S}$, Amaya Lozano J L, Morán Penco J M. Quiste hidatídico en mediastino. Cir Pediatr 2001; 14: 127-8.

2.- Erdogan A, Arife A, Demircan A. Two patients presenting with mediastinal mass. Breathe 2005; 1: 261-3.

3.- Heras F, Ramos G, Duque J L, García Yuste M, Cerezuela L J, Matilla J M. Quistes hidatídicos de mediastino: 8 casos. Arch Bronconeumol 2000; 36: 221-4.

4.- Ramírez M, Donoso A, Daza C, Bravo P. Caso clínico radiológico para diagnóstico. Rev Chil Pediatr 2002: 73; 287-90.

5.- Miranda R, Merchak A, Ferrier P, Villarroel A, Edding O. Quiste hidatídico cardiopericárdico: presentación de dos casos clínicos. Rev Chil Radiol 2002; 8: 123-6.

6.- Álvarez R, Alarcón E, González R. Quiste hidatídico retroperitoneal. Rev Chil Cir 2002: 54; 536-8.

7.- Aliaga F, Oberg C. Epidemiología de la hidatidosis humana en la IX ${ }^{a}$ Región de la Araucanía, Chile 1991-1998. Bol Chil Parasitol 2000; 55 (3-4).

8.- Schenone H, Contreras M, Salinas P, Sandoval L, Saavedra T, Rojas A. Hidatidosis humana en Chile. Seroprevalencia y estimación del número de personas infectadas. Bol Chil Parasitol 1999; 54 (3-4).

9.- Engin G. Acunas B. Hydatid disease with inusual localization. Eur Radiol 2000; 10 : 1904-12.

10.- Salman J, Meriño G, Silva A, Bahamondes J,
Cherres O, Horta J, et al. Hidatidosis intracardíaca. Rev Chil Cir 2000; 52: 285-90.

11.- Pérez J A, Pérez A, Valenzuela M. Quistes hidatídicos primitivos de localización extraabdominal y extrapulmonar. Rev Chil Cir 1999; 51: 341-6.

12.- Borril J, Gemmel M A. An experimental approach to evaluate the potential risk to hydatid disease from inhalation of echinococcus ova. Brit J Surg 1965; 52: 876-8.

13.- Potey V, Jatkar G. Multivesicular mediastinal hydatid cyst. Bombay Hosp J 2004; 46: 56-9.

14.- Eroglu A, Kurkcuoglu C, Karaoglanoglu N. Primary hydatid cysts of the mediastinum. Eur J Cardiothorac Surg 2002; 22: 599-601.

15.- Karnak I, Ciftci A O, Cahit Tanyel F. Hydatic cyst: an unusual etiology for a cystic lesion of the posterior mediastinum. J Pediatr Surg 1998; 33: 759-60.

16.- Berkant Ozpolat, Murat Ozeren, Tolga Soyal, Ertan Yucel. Unusually located intrathoracic extrapulmonary mediastinal hydatid cyst manifesting as Pancoast syndrome. J Thorac Cardiovasc Surg 2005; 129: $688-9$.

17.- Odriozola M, Pettinari R. Relato Oficial. Hidatidosis abdominal. Número Extraordinario Rev Arg Cir 1998.

18.- Pérez Fontana V. El formol y el cloruro de sodio en el tratamiento del quiste hidatídico. Arch Int Hidatid 1961; 20: 315-21.

19.- Aletras H A, Symbas P N. Hydatid disease of the lung. In: Shields TW, ed. General Thoracic Surgery. Philadelphia. Lippicott
Williams \& Wilkins, 2000; 1113-22.

20.- Pedrero Campos C, Sanjuan Rodríguez S, Amaya Lozano J L, Moran Penco J M. Quiste hidatídico en mediastino. Cir Pediatr 2001; 127-8.

21.- Martínez Peralta C. Hidatidosis, complicaciones reiteradas tras lavaje peritoneal salino hipertónico. Rev Argent Cirug 1986; 51: 172-83.

22.- Abu-Eshy SA. Some rare presentations of hydatid cyst (Echinococcus granulosus). J R Coll Surg Edinb 1998; 43: 347-52.

23.- Little J. Recurrence of hydatid disease. World J Surg 1988; 12: 700-4.

24.- Gil-Grande L A, Boixeda D, García-Hoz F, Barcena R, Lledo A, Suarez E, et al. Treatment of liver hydatid disease with mebendazole: a prospective study of thirteen cases. Am J Gastroenterol 1983; 78: 584-8.

25.- Morris D L, Dykes P W, Marriner S, Bogan J, Burrows F, Skeene-Smith H, et al. Albendazole: objective evidence of response in human hydatid disease. JAMA 1985; 253: 2053-7.

26.- Aggarwal P, Wali J P. Albendazole in the treatment of pulmonary echinococcosis. Thorax 1991; 46: 599-600.

27.- Teggi A, Lastilla M G, De Rosa F. Therapy of human hydatid disease with mebendazole and albendazole. Antimicrob Agents Chemother 1993; 37: 1679-84.

28.- Keshmiri M, Baharvahdat H, Fattahi S H, Davachi B, Dabiri R H, Baradaran H, et al. A placebo controlled study of albendazole in the treatment of pulmonary echinococcosis. Eur Respir J 1999; 14: 503-7. 